\title{
Dissecting Tropical Plant Diversity with Forest Plots and a Molecular Toolkit
}

\author{
CHRISTOPHER W. DICK AND W. JOHN KRESS
}

\begin{abstract}
Tropical rainforests are the most biologically diverse of terrestrial biomes. Despite the ecological importance and economic potential of tropical trees, a large fraction of tropical forest tree species lack scientific names, and hundreds of woody plant species in the most intensively studied forest plots remain unidentified. DNA diagnostic tools, including plastid "DNA barcodes" and multilocus genomic markers, can be applied to tropical forest dynamics plots to facilitate taxonomic discovery. Such genetic surveys, as outlined in this article, require expanded herbarium infrastructure and linkages in field ecology, population genetics, and bioinformatics. The fusion of traditional botany and molecular methods will provide baseline data for understanding both the origin and maintenance of tropical plant diversity.
\end{abstract}

Keywords: DNA barcoding, tropical forests, community ecology, phylogeny, taxonomy

$\mathbf{T}$ ropical plant diversity can be intimidating to even the most experienced temperate zone botanists. A single hectare (ha) of tropical rainforest can harbor as many as 900 vascular plant species (Balslev et al. 1998), including up to 450 tree and liana species. The woody plant diversity in such a diverse forest is reminiscent of a botanical garden, in which nearly every stem is an unfamiliar and distinctive taxon. At regional scales within the tropics (figure 1), the woody plant diversity would require encyclopedic field guides for their basic taxonomic description.

Ecologists and evolutionary biologists have made considerable efforts to understand the species richness of tropical forests. Ecologists have been concerned primarily with the assembly and maintenance of species richness at a local scale, which has resulted in empirical and conceptual advances in the field of community ecology (e.g., neutral theory of biodiversity and biogeography; Hubbell 2001). Evolutionary biologists have focused on the description and classification of tropical diversity, and on factors involved in its origin (Schemske 2002). The fieldwork of tropical botany, however, is severely constrained by the necessarily slow pace of taxonomy and by a paucity of tools for species identification. In forest inventory plots of trees more than 10 centimeters $(\mathrm{cm})$ in diameter at breast height in western Amazon forests, for example, about $20 \%$ of the taxa are never identified to the species level (Ruokolainen et al. 2005). Moreover, in some cases diverse understory trees, epiphytes, and lianas are excluded from broadscale biodiversity studies of tropical forests (e.g., ter Steege et al. 2006, Phillips et al. 2009).

While some tropical forest inventory plots have been studied intensively enough to generate comprehensive species lists, botanists have only touched the surface of tropical plant diversity at regional scales (Ruokolainen et al. 2005). For example, although the aforementioned 1-ha forest plot in Amazonian Ecuador holds 900 vascular plant species (Balslev et al. 1998), just 4000 vascular plant species have been reported for the surrounding 7 million ha of Amazon forest in Ecuador (Jørgensen and León-Yánez 1999, Ruokolainen et al. 2005). Further botanical work in remote parts of the Amazon basin and other tropical regions, including Southeast Asia and tropical West Africa, will dramatically increase regional and global species lists (Prance et al. 2000). Estimates of regional species diversity, abundances, and geographic distributions are essential to understanding how species-rich tree communities are assembled (Ricklefs 2004) and how they might be conserved (Hubbell et al. 2008).

\section{The taxonomic bottleneck}

Plant systematists are responsible for most tropical plant identifications, using published regional floras, taxonomic monographs, and comparisons of field specimens with herbarium collections. The technical characters used to distinguish 


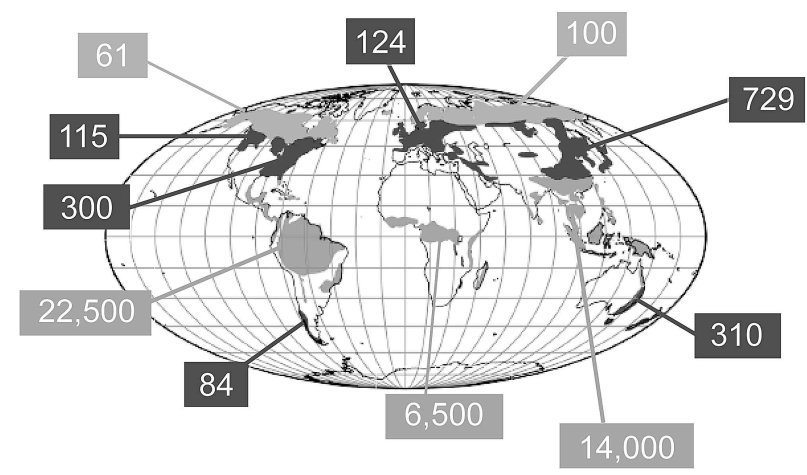

Figure 1. Estimates of the regional number of tree species in moist/wet forests (Fine and Ree 2006) illustrate the latitudinal gradient in tree species diversity.

many species are usually found in flowers or fruits, which are often out of reach for large trees, lianas, and epiphytes, or unavailable in juveniles or species with ephemeral flowering periods. Tropical forests also contain twice the frequency of dioecious (with separate pistillate and staminate plants) tree species as temperate zone forests (Bawa and Opler 1975). Plants with this sexual system can pose an identification problem when flowers of one or the other sex are used in identification. For example, species diagnostic characters are absent in the staminate flowers of some tree species in the nutmeg family (Myristicaceae), which is an important component of tropical forests in Africa, Asia, and the Americas (Newmaster et al. 2008).

More insidious than the challenge of species identification is the fact that many tropical plant species lack scientific names. Taxonomic descriptions are impeded by the limited quantities of herbarium material from remote tropical forests (Prance et al. 2000). Specialists are understandably reluctant to describe new species from a few specimens, and vast swaths of the tropics have never been intensively surveyed because of funding constraints, physical inaccessibility, or political strife, all of which inhibit biodiversity inventory. In addition, for some widespread species, taxonomic detective workin the form of taxonomic monographs-is needed to sort through multiple names (called taxonomic synonyms) given to the same species in different parts of its geographic range (Knapp et al. 2004). Without scientific names and a stable and accessible nomenclature, it is difficult to compare floras from different geographic regions or to develop local field guides. Unfortunately, there is a paucity of systematists to perform these tasks and a coincident shuttering of university museums and herbaria (Wilson 2000, Wheeler 2004).

The urgent need to inventory and manage tropical plant diversity has created a demand for innovative tools to identify species on the basis of characters accessible to botanists in the field. The coming years should see a refinement of electronic aids to species identification, such as digital image recognition algorithms and Web-based interactive identification keys (Gaston and O'Neill 2004, Kress 2004, Agarwal et al. 2006). In this article we discuss the use of DNA markers as tools for species identification and discovery in tropical forests. We argue that a careful integration of herbarium-based research, forest dynamics plots, and genetic markers will advance tropical botany on several major research fronts. With the curated DNA and DNA sequence data available from tropical plant surveys, it will be possible to address questions that link ecology, biogeography, and systematics, and provide a deeper understanding of the processes that generate and maintain tropical plant diversity.

\section{The molecular toolkit: Plastid DNA barcodes}

A DNA barcode, in its simplest sense, is one or more short gene sequences ( $<700$ base pairs) taken from a standardized portion of the genome and used to identify species through reference to DNA sequence libraries or databases (figure 2; Hebert et al. 2003, 2004). The concept of a universally recoverable segment of DNA that can be applied as an identification marker across species has been most successfully applied to animals using the mitochondrial cytochrome $c$ oxidase 1 (COI) gene (Hebert et al. 2004). In part because of the slow rate of evolution in plant mitochondrial DNA (Wolfe et al. 1987), the maternally inherited chloroplast genome has become the primary source of DNA barcodes in plants. Several chloroplast DNA (cpDNA) regions have shown wide applicability, ease of use, and resolution in distinguishing among species of land plants. These include noncoding spacer regions such as $t r n H-p s b A$ (Kress et al. 2005), and protein coding genes such as matK (Lahaye et al. 2008) and $r b c L$ (Kress and Erickson 2007). When used in tandem, coding and noncoding plastid regions can discriminate among closely related species (Fazekas et al. 2008, Newmaster et al. 2008) and amplify broadly across seed plant lineages. The Plant Working Group of the Consortium for the Barcode of Life (CBOL) has selected the $m a t K / r b c L$ combination as the standard DNA barcode marker for seed plants (CBOL Plant Working Group 2009), although a minority of authors suggested that the spacer region $t r n H-p s b A$ is equally useful.

The use of DNA sequences as tools for taxonomy has a long precedence in the field of molecular systematics. While systematics traditionally emphasizes evolutionary relationships within clades, many DNA barcode projects are designed to survey the polyphyletic assemblages that comprise ecological communities. It is not surprising that tropical field biologists, whose work would be vastly improved by accurate species identifications, are among the most ardent supporters of DNA barcoding (Janzen 2004a, Kress and Erickson 2008). Ecologists would benefit from DNA markers that accurately identify herbivore host plants lacking diagnostic flowering features, disarticulated fruits, seeds and seedlings, plant fragments in animal guts and scats, as well as the underground root ecology of rainforest trees (Kress and Erickson 2008).

A number of biologists, however, have criticized both the premise and scope of DNA barcoding. Species cannot be precisely identified using DNA barcodes, for example, if variation in the DNA barcodes among species is low (Hickerson 


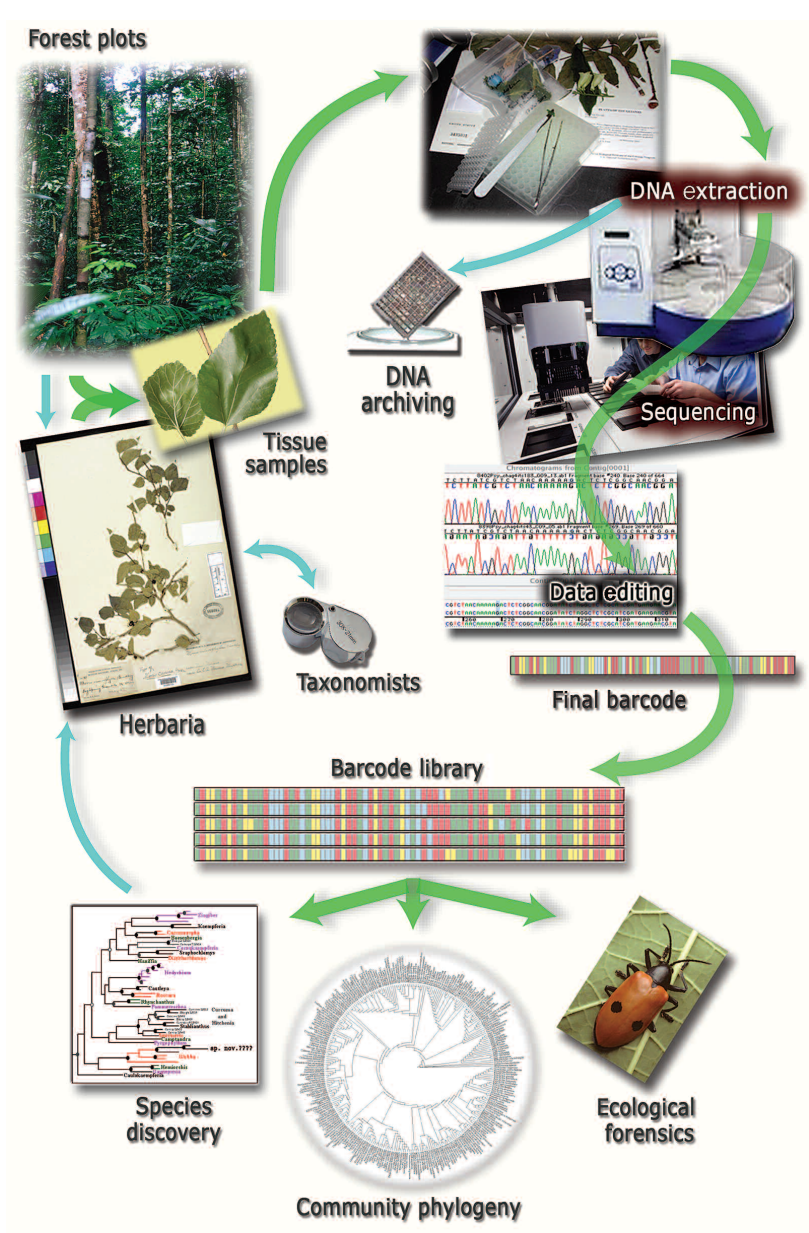

Figure 2. Steps involved in DNA barcoding and some downstream analyses of trees sampled from tropical forest inventory plots. In this model, plant systematists receive diagnostic herbarium material, DNA sequence, and ecological data for use in the taxonomic identification and description of new species. All of these processes lead to the establishment of a DNA barcode reference library.

et al. 2006, Elias et al. 2007), if related species retain ancestral polymorphisms, or if they have a history of hybridization (Moritz and Cicero 2004, Meyer and Paulay 2005). Some of the same considerations apply to identifications based strictly on morphology. Thus, for closely related species or problematic taxa such as hybridizing oaks or apomictic hawthorns, DNA barcodes should be considered one line of data available to test taxonomic hypotheses, not an infallible identification criterion. There is justified concern in the systematics community that DNA barcode initiatives will compete with basic taxonomic research. However, a similar tension has existed in the past between molecular phylogeny and morphological systematics (Wheeler 2004). DNA barcoding should be considered an additional tool of taxonomy, which at best can help to identify sterile specimens lacking taxonomic characters, uncover cryptic species, and provide evidence that some species may be inappropriately split. Like field guides, DNA barcodes can identify only species that have already been described and named. The broad utility of DNA barcoding in tropical forests therefore depends on a corresponding increase in systematics research on tropical clades. DNA barcodes will never replace traditional taxonomy, but rather will serve to further its goals.

\section{Nuclear DNA markers}

Tropical rainforests have been characterized both as cradles of speciation, which predict many species of recent origin, and as museums of taxa in which tree lineages have accumulated since the early rise of angiosperms (Stebbins 1974). The older diversity is evident in the taxonomic structure of tropical forest tree communities, which can be rich in families and genera as well as in species. For example, the Yasuní 50-ha forest inventory plot in Ecuador (figure 3) contains more tree genera $(n=333)$ than the tally of native tree species (approximately 300 ) in moist forests of eastern North America (figure 1; Valencia et al. 2004). Yet the Yasuní forest plot also contains sympatric species of recent origin, including 43 species from the species-rich tree genus Inga (about 300 species), which probably originated during the past two million years (Lavin 2006). The DNA barcode implication of this explosive radiation is that many species of Inga share similar, if not identical, plastid DNA sequences (Richardson et al. 2001).

The chloroplast genome is a single, nonrecombining locus that reflects a single gene genealogy, which may differ substantially from actual species phylogeny (Edwards 2008). The consensus of nonrecombining nuclear genes more precisely reflects the species trees and can be used to diagnose ancestral polymorphism and hybridization. Plant systematists have not taken advantage of nuclear DNA sequences to the extent that zoologists have, and only a few nuclear regions, such as the internal transcribed spacer (ITS) of nuclear ribosomal DNA, are employed broadly across seed plant lineages. Nextgeneration DNA sequencing techniques, which can simultaneously generate DNA sequences from hundreds of nuclear loci, will provide the potential to screen for polymorphic genomic markers that are selectively neutral or linked to important adaptive genes (Namroud et al. 2008).

Simple sequence repeats (SSRs, also known as microsatellites) are codominant genetic markers (in which heterozygotes may be distinguished) used in population genetic analyses. $\mathrm{Du}-$ minil and colleagues (2006) showed how nuclear SSR loci (nSSRs) can be used as a tool for taxonomic discovery. The authors used nSSRs in individual-based clustering algorithms (Pritchard et al. 2000) to discern genetic demes within a set of morphologically similar species of Spanish mahogany (Carapa, Meliaceae) in French Guiana. Reproductive isolation cannot be attributed to geographic distance when the genetic demes are sympatric, and hence the demes are likely to correspond with reproductively isolated biological species. This approach has been called a "blind population genetic survey" (cf. Duminil et al. 2006) because it does not involve prior taxonomic classification of the sampled individuals. In addition 
to geographic structure and gene flow, nSSR markers can be used to detect hybridization and the existence of apomixes and clones (Dick et al. 2008). A major disadvantage of nSSRs is their expensive and laborious development, the relatively large sample sizes of individuals (e.g., $n \geq 30$ ) needed for population analyses, and the low transferability of anonymous nSSRs for use across species.

There is a promising alternative to nSSRs developed from anonymous genomic regions: nSSRs derived from expressed sequence tags (EST-SSRs) (Bouck and Vision 2007). Expressed sequence tags are short DNA fragments of expressed genes obtained from messenger RNA (mRNA) in the cellular cytoplasm. Although introns are spliced from mRNA during transcription, the untranslated regions at the 3 ' and 5 ' ends of the mRNA contain SSRs at a frequency of $1 \%$ to 2\% (Ellis and Burke 2007). Because EST-SSR loci are adjacent to coding sequences, highly conserved polymerase chain reaction (PCR) primers can be designed; these PCR primers are transferable across species and higher-level taxa (Ellis and Burke 2007), and they do not produce null alleles (unamplified alleles) as frequently as anonymous nSSRs do. Although EST-SSR markers have not been widely used in tropicalplant biodiversity studies, more than 52 million EST sequences are available in GenBank, many of which are derived from ecologically dominant tropical tree families such as the legumes (Fabaceae), coffee (Rubiaceae), and mahogany (e.g., Choi et al. 2006).

\section{Tropical forest plots}

DNA barcoding has the potential to integrate species identification across distantly separated tropical forests, yet broad geographic sampling brings additional challenges. First, if collections span geographic barriers, it can be difficult to disentangle geographic divergence from between-species variation. Second, herbarium specimens from which DNA can be extracted may not be available for all species across a wide geographic scale, and it may be difficult to return to remote locations to obtain diagnostic voucher collections. One solution is to focus efforts on networks of permanent forest plots whose trees and shrubs have been mapped and are readily accessible. By working within sites, researchers can evaluate the taxonomic variation among sympatric taxa and obtain high-quality herbarium specimens through repeated visits. In forest inventory plots that are monitored over time, variation in functional traits such as germination ecology, leaf physiology, and demographic structure can distinguish otherwise cryptic species (e.g., Silvera et al. 2003).

The Center for Tropical Forest Science (CTFS), headquartered in the Smithsonian Tropical Research Institute (STRI), coordinates a network of 22 large-scale (15 to $52 \mathrm{ha}$ ) tropical forest dynamics plots with counterparts in 16 tropical countries (figure 4). Each CTFS plot contains hundreds of thousands of mapped trees $(\geq 1 \mathrm{~cm}$ in diameter at breast height) that are monitored at five-year intervals for growth, recruitment, and mortality. For example, the 50-ha plot on

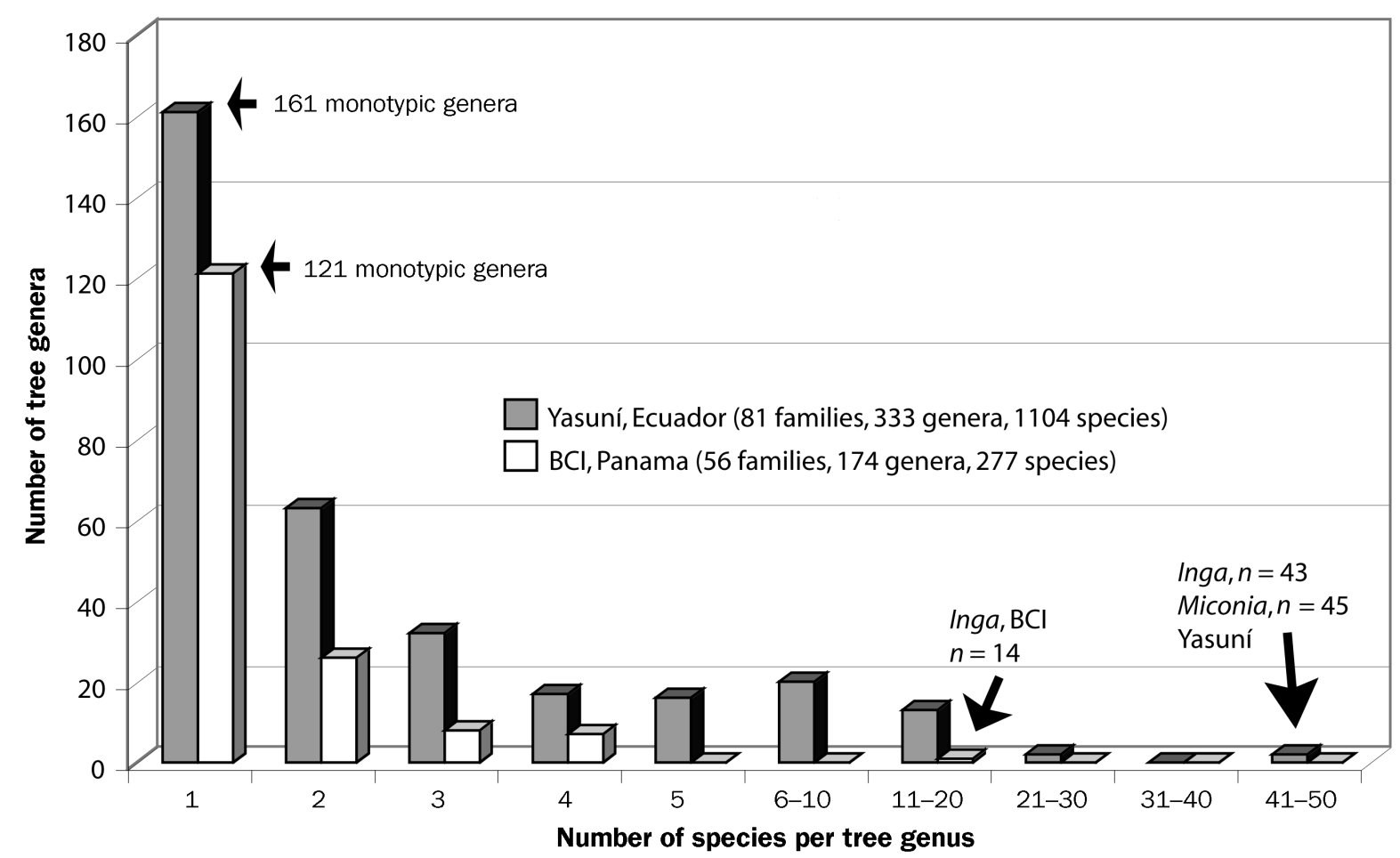

Figure 3. Tropical forests often contain a high diversity of tree species distributed across many genera and families. The majority of tree genera contain fewer than three species in 50-hectare forest plots in Panama and Ecuador (see figure 4 for locations). The higher-level taxonomic diversity of sympatric species facilitates the use of slowly evolving plastid DNA barcodes for species identification. Source: Modified from Bermingham and Dick (2001), with permission from the American Association for the Advancement of Science. 


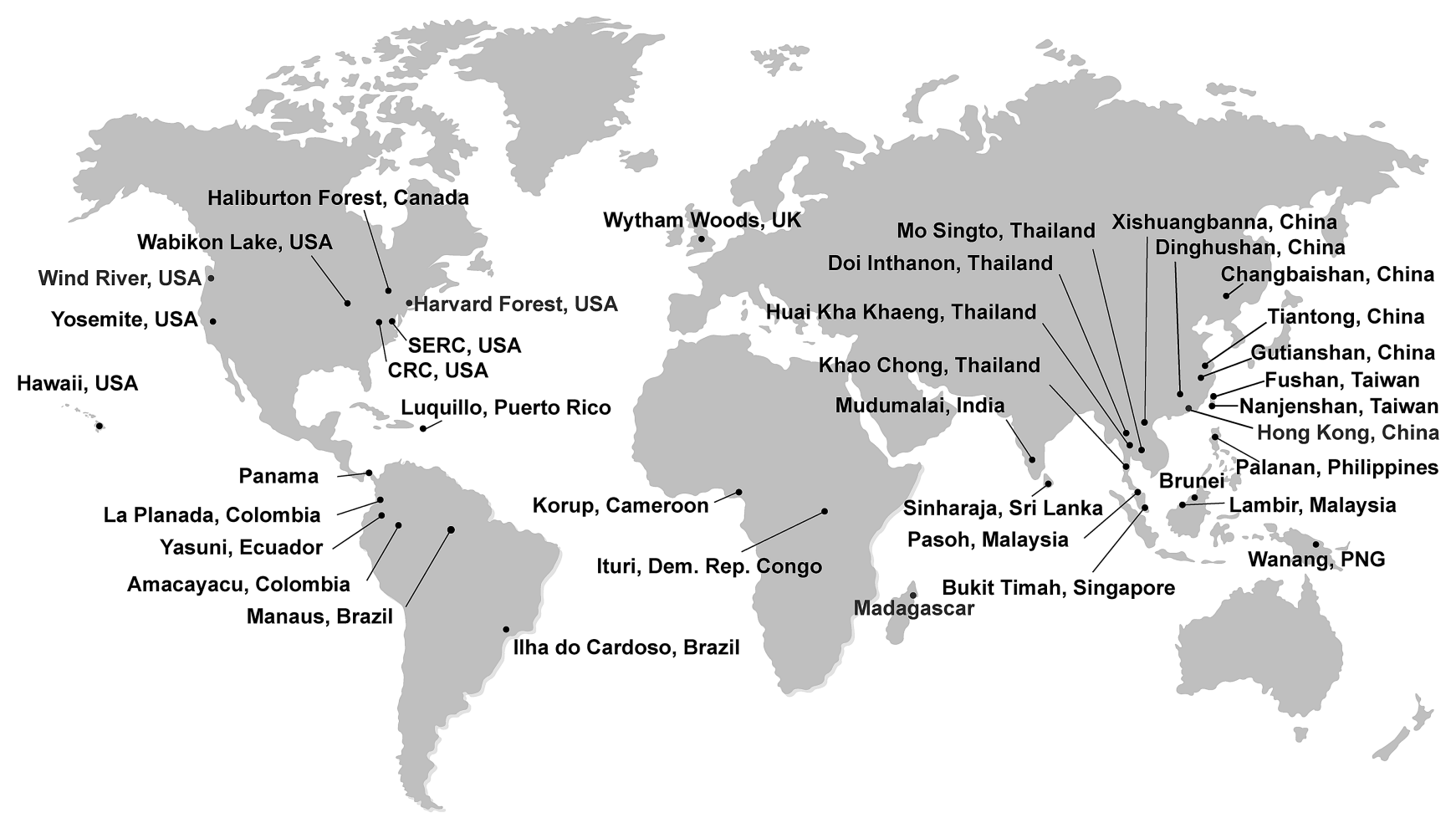

Figure 4. The Center for Tropical Forest Science maintains a network of 34 permanent forest dynamics plots in 20 host countries (www.ctfs.si.edu). These plots contain an estimated 7500 tree species. Abbreviations: CRC, Conservation and Research Center; SERC, Smithsonian Environmental Research Center.

Barro Colorado Island (BCI), Panama, contains more than 250,000 individual stems and has been monitored for more than 25 years (Hubbell and Foster 1983). The 34 temperate and tropical forest plots contain more than 3.5 million tagged trees and an estimated 7500 tree species. A new initiative at the Smithsonian, called the Smithsonian Institution Global Earth Observatories (SIGEO), together with CTFS, the Arnold Arboretum at Harvard University, and other partners, is expanding this monitoring program by adding large-scale plots in the temperate zone to quantify the response of trees and forest ecosystems to Earth's changing climate. The SIGEO is a member of the Group on Earth Observations, a consortium launched in 2002 that recently established the Global Earth Observation System of Systems (www.earthobservations.org) to provide access to data, services, analytical tools, and modeling capabilities for environmental decisionmaking in response to biodiversity loss and climate change (Scholes 2008).

The combined efforts of the CTFS and its partner institutions in establishing and maintaining forest dynamics plots in tropical Asia, Africa, and the Americas offer an unparalleled opportunity to characterize the woody plant diversity of "living museums," which contain an estimated $12 \%$ of all known tropical tree species. A comprehensive DNA-based botanical inventory in these plots would require the collaboration of systematists, molecular biologists, and informatics specialists, as well as a significant financial investment. However, it could jump-start the process of species discovery in tropical forests while refining the taxonomic resolution of species that are already being studied by ecologists.

DNA barcoding in two Neotropical forests. Scientists at the STRI and the Smithsonian's National Museum of Natural History have initiated a DNA barcode survey of the 296 shrub and tree species (in 180 genera, 49 families, and 21 orders) currently recorded in the BCI forest dynamics plot in Panama. To date, at least one locus of the three-locus $r b c L / t r n H-p s b A / m a t K$ plant barcode combination (Kress and Erickson 2007) has been successfully sequenced for $98 \%$ of the total species; of these 290 species, $98 \%$ have unique genetic signatures that distinguish each of them from the other woody species in the plot (Kress et al. 2009). The high level of discriminatory power is due in part to the phylogenetic diversity of BCI trees, such that most interspecific comparisons involve distantly related taxa (figure 5). Some species from diverse genera (Ficus, Inga, and Piper) are indistinguishable with DNA barcodes, but these problematic taxa represent fewer than $2 \%$ of the species in the BCI plot. This initial barcode survey has also pointed out the challenge of correctly identifying the hundreds of thousands of stems solely through use of traditional taxonomic methods based on vegetative traits only.

In the Nouragues field station in French Guiana ( $w w w$. nouragues.cnrs.fr), a team of European researchers (see the BRIDGE project at http://ecofog.cirad.fr/Bridge) has performed a DNA barcode survey of 1028 trees (diameter at breast height $\geq 10 \mathrm{~cm}$ ) in two 1-ha plots. These 2 ha of diverse 


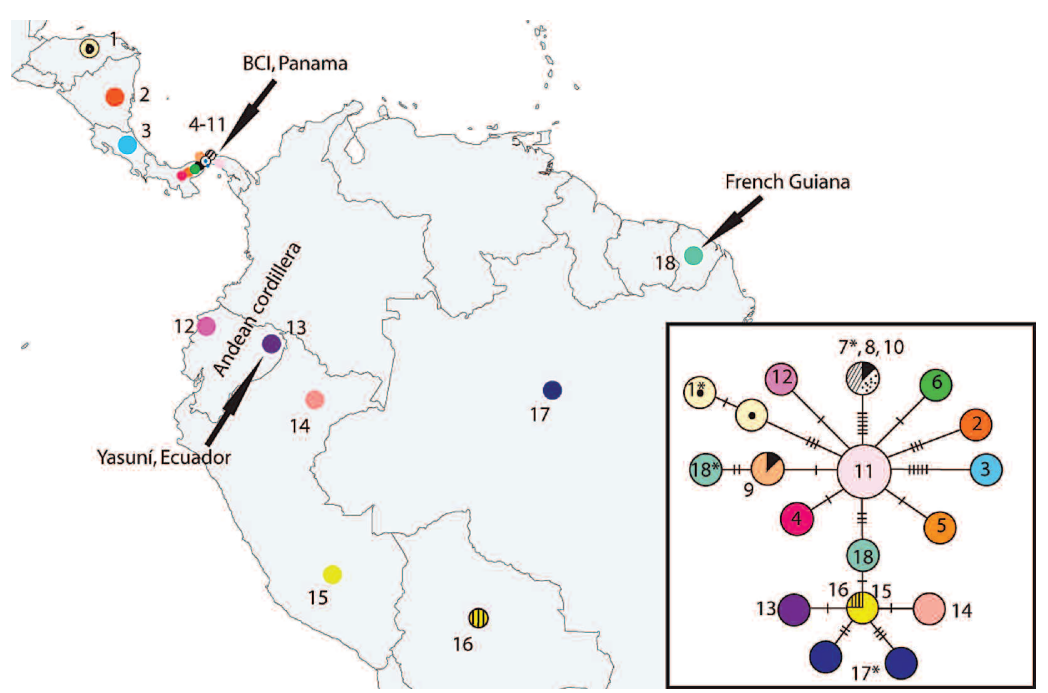

Figure 5. Some widespread tree species contain high levels of DNA barcode variation. The widespread species Symphonia globulifera contained 18 haplotypes (circles) in 18 Neotropical sites (colors) of the plastid DNA barcode region trnH-psbA. The embedded haplotype network shows mutational differences as hatch marks. The Barro Colorado Island, Yasuni, and Nouragues forest plots are indicated with arrows. Source: Modified from Dick and Heuertz (2008), with permission from Wiley-Blackwell. geographic sampling of one of the shared species, Symphonia globulifera, revealed 18 trnH-psbA haplotypes in 18 Neotropical populations (figure 5; Dick and Heuertz 2008). Although long distances separated most sample sites, each of eight populations sampled within Panama was fixed for distinct trnH-psbA haplotypes. Symphonia globulifera is a shade-tolerant species whose Neotropical populations date to the Miocene (Dick et al. 2003). It is likely that other widespread tree species will display high levels of geographic variation in the DNA regions selected for molecular inventories. The geographic variation can be useful for such applications as wood forensics, in which the geographic provenance of a tree must be known (Deguilloux et al. 2002).

Although the morphological uniformity of $S$. globulifera suggests that Panama and French Guiana populations are part of a unitary widespread species, this may not hold true for hundreds of other putative tree species shared between Central and South America. In some cases, distinct species might be erroneously combined using a genetic criterion, as in some Inga. In other cases, such as in Symphonia, high levels of nucleotide divergence Guiana Shield forest have thus far yielded 255 tree species from 129 genera and 48 families. In trials with seven plastid DNA regions, the BRIDGE team also had the best success in amplification and species discrimination (>90\%) using the trnH-psbA/rbcL combination (Gonzalez et al. 2008). The team used ITS sequences to discriminate among species in the Sapotaceae family that had invariant cpDNA barcodes. A preliminary GenBank query of sequences obtained from 100 trees (about 72 species) foreshadowed the limitations of the current DNA reference library maintained in GenBank. The partial $r b c L$ sequences matched to only $20 \%$ of species and $80 \%$ of genera in the library. Because $r b c L$ is widely used in plant molecular systematics (although usually invariant within genera), the match rate in GenBank for less widely used loci, such as $\operatorname{trnH}-p s b A$, should be much lower.

In addition to these two tropical forest plots, efforts to initiate the building of a DNA barcode library of plant taxa are now under way at CTFS plots in Papua New Guinea, China, Taiwan, Singapore, and Puerto Rico, as well as at the La Selva Biological Field Station in Costa Rica, operated and managed by the Organization for Tropical Studies. As the number of tropical forest plots with comparative DNA sequence data increases, it will be possible to compare phylogenetic diversity (see below) across a variety of forest types and biogeographic regions around the world.

Taxonomic integration. Despite site variation in soils and precipitation and the geographic separation of more than 2000 kilometers over geographic barriers that include the Andes and the dry Caribbean shoreline, the BCI and Nouragues forest plots share at least 109 tree genera and 70 tree species. Extensive among sampling locations are cause for closer systematic studies. The ability of tropical botanists to separate allopatric species from geographic populations will ultimately depend on the geographic coverage of the DNA reference collections, the quality of the associated herbarium specimens, and careful study of morphological variation by systematists.

To scale up to regional levels and match conspecific individuals that may have divergent plastid DNA sequences, genetic survey data must be linked to canonical physical herbarium specimens, and preferably linked also to ecological data (e.g., such as site description and location) and field characters (e.g., bark, trunk morphology, etc.). It is essential to plan for and fund the institutional curation of the physical reference collections, which include standard herbarium specimens, frozen tissue collections, and archived DNA samples. Each of these types of collections requires a separate method of curation (for example, metal herbarium cabinets versus liquid nitrogen storage containers versus refrigerated sample plates), which are all interlinked through a common bioinformatics data maintenance and retrieval system. The genetic data and voucher material provide a stable, long-term source of descriptive information about species and individuals, which will serve as the foundation for future taxonomic decisions and nomenclatural changes. The archival DNA will be needed for further molecular systematic investigations.

\section{Biodiversity informatics}

It has been estimated that more than 270 million plant specimens exist in more than 2600 herbaria in over 147 countries 
(Holmgren et al. 1990). These specimens have served as the basis for documenting, describing, and naming hundreds of thousands of plant species. The great majority of these specimens have also provided information on morphological, habitat, and distributional characteristics of plant species. Yet despite the great abundance of herbarium collections, many areas of the Earth, especially in the tropics, remain undersampled because of access difficulties (Prance et al. 2000). The large-scale efforts to perform DNA surveys of tropical forest plots will greatly supplement these existing specimen records and add a new dimension to the biodiversity information obtained from them.

The most significant informatics tool for DNA barcoding is the Web-based Barcode of Life Data Systems (BOLD) maintained at the University of Guelph, Canada. BOLD, an electronic platform for barcode records, chromatograms, species identification algorithms, and digital images of voucher specimens for animals (Ratnasingham and Hebert 2007), was developed to handle the soaring number of single-locus CO1 barcodes for the many groups of animals now under investigation. Eventually all $\mathrm{CO} 1$ barcodes will be transferred with a specific "barcode" tag from BOLD to the barcode repository in GenBank. A new suite of informatics and analytic tools will be required for the multilocus system that serves the non-COI plant data (currently under development at BOLD and at the Smithsonian). This system will allow for the management of sequence data, metadata associated with each accession or species (e.g., voucher specimens and locality data), and links to online image libraries and other databases (e.g., the CTFS forest dynamics plot data). Tools for analyses must include an identification search engine, similar to those employed by GenBank and BOLD, to allow users to submit a sequence for comparison to sequences archived in the DNA barcode library, and analytic techniques for building community phylogenies (see below).

Equally important to the informatics tools for barcoding will be the institutional curation of plant DNA and voucher specimens. The basic plant barcode library requires specimens and tissue samples from 5 to 10 individuals per species of plant. The global plant DNA barcode initiative espoused by CBOL ( $w w w$.barcoding.si.edu) would produce several million new plant vouchers within a few years. Such an influx of specimens will increase by hundreds of thousands the number of specimens currently being added to the world's herbaria each year through programs of species inventory and surveys. This will require a parallel increase in the infrastructure for accessioning, mounting, databasing, and storing these voucher specimens, tissue samples, and DNA extractions. Without careful planning of the curatorial component of biodiversity inventory, DNA barcode initiatives may yield only shortterm scientific benefits.

Freshly collected leaf samples provide the best DNA for sequencing and archiving, but it is not feasible to replicate the millions of collections already available in the world's herbaria for the purpose of making reference DNA collections. Although it can be difficult to obtain consistent, high-quality
DNA sequences from many herbarium specimens, such specimens are readily accessible, and many are now referenced online in databases such as TROPICOS, which is maintained by the Missouri Botanical Garden. With appropriate research, the ability to extract useful DNA from this rich source of species will very likely improve.

Species discovery. As has already been demonstrated with animal DNA barcodes (Hebert et al. 2004), a spectrum of new plant species will be discovered and described as a result of tropical tree inventories based on both plastid and nuclear DNA markers. If closely related species are adequately represented as DNA and herbarium specimens, the outliers (in terms of morphology or DNA) can be provided to specialists for closer inspection. Upon request, field biologists can give further information to the specialist (Janzen 2004b). This collaborative process is illustrated by the pioneer tree species Trema micrantha (Ulmaceae), which is distributed in secondary forests throughout the Neotropics. In the BCI forests, T. micrantha individuals were found to contain divergent plastid and ITS haplotypes, which placed the outlying individuals in different clades within the genus (Yesson et al. 2004). Further ecological study showed that the two genetically divergent Trema species partitioned habitats along light gradients (Silvera et al. 2003) and exhibited subtle differences in fresh fruit color. The combined genetic and ecological data led to the discovery of a new tree species after more than 25 years of demographic research on what had been thought to be a single species.

DNA surveys in the intensively studied forest plots are likely to uncover many more species in the diverse forests of the Amazon and Southeast Asia. An intensive survey of the Ducke forest reserve near Manaus, Brazil (population > 2 million), for the development of a field guide resulted in the discovery of 55 plant species new to science (Prance et al. 2000). The Manaus region is one of the most heavily collected sites in Amazonia. Forest inventory plots in more remote regions are likely to yield much longer lists of new species. In the Yasuní forest inventory plot, for example, only 548 of 1104 tree species were identified to the species level after six years of research done in collaboration with systematists (Valencia et al. 2004). Many of these tree species will be new to science, particularly in some diverse families such as the avocado (Lauraceae) and coffee (Rubiaceae) families. Study of the mapped trees can reveal the attributes of newly described species, such as microsite preferences or mating system. The DNA information, vouchers, and metadata captured as part of the process of DNA barcoding and molecular studies will facilitate systematists' description of new species.

\section{Twenty-first century directions}

Genetic surveys of tropical forests, especially those that are anchored in forest dynamics plots, can be a springboard into research on the biogeography, evolutionary history, and ecology that generate and maintain tropical tree communities. These advances may not necessarily result from the DNA sequence 
data provided by DNA barcodes themselves, but rather from the availability of genomic DNA, herbarium vouchers, and mapped trees for downstream analyses.

Ecological forensics. In tropical forests, specialized herbivores and pathogens are thought to play an inordinate role in regulating the population densities of tree species that might otherwise become dominant (Leigh et al. 2004). The degree of host plant specialization is largely unknown, however, and it is difficult to link a beetle or caterpillar to a host plant unless it is observed in the act of feeding. Plant DNA barcodes can be used to identify the gut contents of insects and definitively link herbivores to their host plants. Jurado-Rivera and colleagues (2009) identified gut contents of 76 species of Australian leaf beetles (Chrysomelidae) using the P6 intron of the plastid trnL (UAA) gene (Valentini et al. 2009). The authors confirmed that most beetles were specialized to the level of plant genus (Eucalyptus, Acacia), but some taxa had unexpectedly broad host associations. The host plants could not be identified to the species level because only 14 of the 1000 described Australian species of Eucalyptus, and 15 of the 800 Acacia species, were represented in GenBank by $\operatorname{trnL}$ sequences. Studies focused on local communities with complete DNA barcode reference libraries will avoid this problem and provide new insights into insect-host interactions.

The root zone is a frontier of tropical forest ecology that could be opened up with DNA barcode approaches. Belowground competition partly determines the patterns of species coexistence, and roots account for a large proportion of forest biomass. In a pioneering study in central Texas, Jackson and colleagues (1999) used ITS to identify roots sampled from the ceilings of caves at different subsurface depths. Six tree species had roots extending below 5 meters, and one species tapped to a depth of 25 meters. Information about root architecture and root depths helps predict how different species will fare under drought conditions. Furthermore, the interactions of roots from different species indicate potential to transfer fungal pathogens as well as mutualistic fungi.

The DNA obtained from dried wood can be useful for regulating trade in endangered tree species (Deguilloux et al. 2002), and DNA markers can be used to identify standing dead trees and assess the impacts of drought and other environmental stresses on forest structure. Phillips and colleagues (2009) found high tree mortality in 136 forest inventory plots scattered across the Amazon basin. Since some species experience differentially higher mortality than others, one might predict how community structure may change under scenarios of drought stress associated with global climate change. In these plots, trees are not identified to the level of species. DNA barcodes from the standing dead trees could be used to identify the most vulnerable species in these forests.

Community phylogeny. DNA sequence information provides an evolutionary dimension to biodiversity measures by incorporating the genetic (i.e., branch length) distance among coexisting taxa (figure 6). New statistics have been developed that incorporate phylogenetic distance into metrics of biodiversity, such as species richness (Helmus et al. 2007) and beta diversity (Hardy and Senterre 2007). Phylogenies of tree communities are increasingly used to test hypotheses regarding the process of community assembly and local species coexistence (Vamosi et al. 2009). Community phylogenetic structure may be estimated by counting the nodes (e.g., genus, family, order) that lead back to the common ancestor, which is typically done using the Angiosperm Phylogeny Group (APG) seed plant phylogeny (Stevens 2001 et seq.). Alternatively, fossil-calibrated phylogenies (Wikstrom et al. 2001) provide branch lengths that correspond to time since divergence. Software packages such as Phylomatic (Webb and Donoghue 2005) construct phylogenies using plant species lists and published trees.

If ecological traits were conserved through evolutionary time, one would expect closely related species to occur in similar habitats (phylogenetic clustering). However, closely related species are also likely to be strong competitors because of their ecological similarities, which may result in competitive exclusion (phylogenetic overdispersion) at very local scales. In contrast to these deterministic aspects of community assembly, neutral theory (Hubbell 2001) places primary importance on seed dispersal limitation rather than on competition or niche filtering. Using the mapped trees of the BCI plot, Kembel and Hubbell (2006) found that tree species in the younger forest and on drought-stressed plateaus were phylogenetically clustered, whereas species in the swamp and slope habitats were phylogenetically overdispersed. These results suggested that conserved ecological traits are favored in stressful habitats, and species composition in the slope and swamp habitats may have been driven by local competition.

Phylogenetic information from focal plant communities can be incorporated into the APG phylogeny to provide greater phylogenetic resolution at the branch tips, and thereby improve some estimates of community phylogenetic structure (Swenson 2009). Both maximum likelihood and parsimony phylogeny reconstruction using the $r b c L$, $\operatorname{trnH}-p s b A$, and
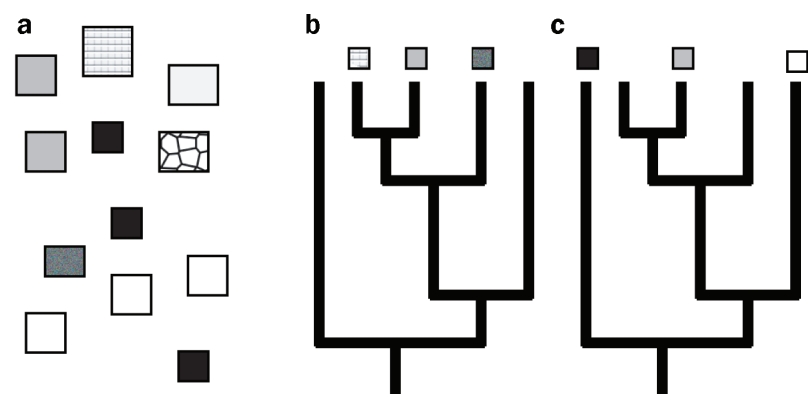

Figure 6. Phylogenetic diversity (phylodiversity) incorporates the branch lengths to the common ancestor of species pairs into estimates of alpha and beta diversity. For three species selected from species pool (a), scenario (c) has the greatest phylodiversity because the combined branch length distance to the common ancestors is greater than in (b). 
mat $K$ barcode sequences from 281 species in the BCI plot generated phylogenetic hypotheses that were surprisingly highly congruent with the APG phylogeny (Kress et al. 2009). Genealogical resolution within families was much higher than the APG phylogeny, and the fast-evolving intergenic spacer and coding gene provided resolution to the species level. The archival DNA now available for all of the sampled trees may provide further phylogenetic resolution by adding gene regions for projects geared toward specific lineages rather than just species identification.

Regional species pools. Integrating systematics and DNA surveys of tropical forests is a necessary step in characterizing the regional species pool from which local communities are derived. With large forest inventory plots as an initial source of DNA and reference vouchers, DNA surveys can be performed in surrounding networks of smaller plots. For example, a network of semipermanent, small (approximately $0.1 \mathrm{ha}$ ) forest inventory plots distributed across the Amazon basin has been used to study the demographic and biomass response of tropical woody plants to global climate change (Phillips et al. 2009). The DNA surveys in these forest plots would permit more precise taxonomic identifications, integration of taxonomy across the plots for precise estimates of beta diversity, and monitoring of species-level variation in response to climate changes. The steady accumulation of new species, including the sampling of rare species, would enable more accurate estimation of total diversity of tree species in tropical forests, and provide empirical estimates of regional tree species diversity (Gerhold et al. 2008, Hubbell et al. 2008).

Finally, DNA and herbarium samples from phylogenetically diverse tropical forests could be used to fill taxonomic gaps in higher-level phylogenies and, in combination with fossil and geographic information, to evaluate the biogeographic history of the regional species pool. Phylogenetic analysis of tree species in the Yasuní plot, for example, has yielded insights into the continental-scale assembly of Amazon forest trees (Pennington and Dick 2004). For several decades, the Amazon flora was thought to have resisted major intercontinental immigrations after the breakup of western Gondwana (Raven and Axelrod 1974, Gentry 1982). However, fossil-dated phylogenies of ecologically dominant Amazon tree families indicate that they are too recent for Gondwana origins, and that they originated outside South America. Of the 1104 tree species identified in the Yasuní forest, 232 (21\%) belonged to families and genera classified as immigrants (Pennington and Dick 2004). Some of the immigrant lineages may have arrived directly from Africa through marine dispersal, as was the case of Symphonia globulifera (Dick et al. 2003), while others may have crossed the Panama land bridge from Central America. The finding that many tropical tree lineages have established around the world via oceanic currents explains some of the taxonomic similarities in the forests of tropical America, Asia, and Africa.

\section{Conclusions}

The field of systematics has struggled through the centuries to fulfill somewhat disparate aims that include inventorying the world's species, establishing a stable taxonomic nomenclature for communicating those species, and proposing classifications that reflect the evolutionary history of those species and higher taxa. In the tropics, where more species of plants are found than in any other habitat, the emerging application of DNA surveys and inventories may begin to more effectively unify these activities. Certainly, the lure of new phylogenetic hypotheses for clades and communities will be an important outcome of DNA collections, perhaps even more so than accurate species identification using multilocus DNA barcodes. Research efforts aimed at addressing testable hypotheses, as opposed to the goal of having DNA barcode information for all plants, may be the ultimate driving force behind the use of DNA surveys across a wide set of tropical plant species.

The scientific potential of genomic approaches in the exploration and analysis of tropical forest plant diversity is great. But to realize the scientific goals outlined in this article, the proponents of DNA surveys may need to focus less on technologies that permit mass processing of DNA samples and more on linkages between ecologists, population geneticists, and systematists, including the provision of adequate funding for systematic research and herbarium infrastructure. Funding is necessary not only for long-term curation of DNA and voucher specimens but also for training a new generation of systematists to name and biologically interpret cataloged species. It is especially important to train systematists in developing countries, where most of the remaining diverse tropical forests are found. If done properly, the DNA surveys focused on tropical forest inventory plots will accelerate the cataloging of tropical diversity and foster a deeper understanding of its evolutionary origin and ecological resilience.

\section{Acknowledgments}

Bill Laurance first suggested that we prepare this article. We would like to thank Mailyn Gonzalez and Jérôme Chave for providing information on the BRIDGE project, the TROPIBIO seminar group at the University of Michigan for fruitful discussion, and Brian Sedio and Ida Lopez for help with some of the figures. Paul Berry, Toby Pennington, David Erickson, and Paul Fine provided useful comments on the manuscript. The authors thank the Center for Tropical Forest Science (CTFS) and the Smithsonian Tropical Research Institute for the invitation to participate in a workshop on evolutionary processes in the CTFS network of plots. C. W. D. acknowledges the support of the National Science Foundation (DEB 043665).

\section{References cited}

Agarwal G, et al. 2006. First steps toward an electronic field guide for plants. Taxon 55: 597-610.

Balslev H, Valencia R, Paz y Miño G, Christensen H, Nielsen I. 1998. Species count of vascular plants in one hectare of humid lowland forest in Amazonian Ecuador. Pages 585-594 in Dallmeier F, Comiskey JA, eds. 
Forest Biodiversity in North, Central and South America, and the Caribbean: Research and Monitoring, vol. 21. UNESCO.

Bawa KS, Opler PA. 1975. Dioecism in tropical forest trees. Evolution 29: 167-179.

Bermingham E, Dick C. 2001. The Inga: Newcomer or Museum Antiquity? Science 293: 2214-2216.

Bouck A, Vision T. 2007. The molecular ecologist's guide to expressed sequence tags. Molecular Ecology 16: 907-924.

CBOL Plant Working Group. 2009. A DNA barcode for land plants. Proceedings of the National Academy of Sciences 106: 12794-12797. doi:10.1073/pnas.0905845106

Choi H-K, Luckow MA, Doyle J, Cook DR. 2006. Development of nuclear gene-derived molecular markers linked to legume genetic maps. Molecular Genetics and Genomics 276: 56-70.

Deguilloux MF, Pemonge MH, Petit RJ. 2002. Novel perspectives in wood certification and forensics: Dry wood as a source of DNA. Proceedings of the Royal Society B 269: 1039-1046.

Dick CW, Heuertz M. 2008. The complex biogeographic history of a widespread tropical tree species. Evolution 62: 2760-2774.

Dick CW, Abdul-Salim K, Bermingham E. 2003. Molecular systematics reveals cryptic Tertiary diversification of a widespread tropical rainforest tree. American Naturalist 162: 691-703.

Dick CW, Hardy OJ, Jones FA, Petit RJ. 2008. Spatial scales of pollen and seedmediated gene flow in tropical rain forest trees. Tropical Plant Biology 1:20-33.

Duminil J, Caron H, Scotti I, Cazal SO, Petit RJ. 2006. Blind population genetics survey of tropical rainforest trees. Molecular Ecology 15: 3505-3513.

Edwards SV. 2008. Is a new and general theory of molecular systematics emerging? Evolution 63: 1-19.

Elias M, Hill RI, Willmott KR, Dasmahapatra KK, Brower AVZ, Mallet J, Jiggins CD. 2007. Limited performance of DNA barcoding in a diverse community of tropical butterflies. Proceedings of the Royal Society B 274: 2881-2889.

Ellis JR, Burke JM. 2007. EST-SSRs as a resource for population genetic analyses. Heredity 99: 125-132.

Fazekas AJ, Burgess KS, Kesanakurti PR, Graham SW, Newmaster SG, Husband BC, Percy DM, Hajibabei M, Barrett SCH. 2008. Multiple multilocus DNA barcodes from the plastid genome discriminate plant species equally well. PLoS ONE: e2802.

Fine PVA, Ree RH. 2006. Evidence for a time-integrated species-area effect on the latitudinal gradient in tree diversity. American Naturalist 168: 796-804.

Gaston KJ, O’Neill MA. 2004. Automated species identification: Why not? Philosophical Transactions of the Royal Society B 359: 655-667.

Gentry A. 1982. Neotropical floristic diversity: Phytogeographical connections between Central and South America, Pleistocene climatic fluctuations, or an accident of Andean orogeny? Annals of the Missouri Botanical Garden 69: 557-593.

Gerhold P, Pärtel M, Liira J, Zobel K, Prinzing A. 2008. Phylogenetic structure of local communities predicts the size of the regional species pool. Journal of Ecology 96: 709-712.

Gonzalez M, Baraloto C, Engel J, Mori SA, Petronelli P, Riera B, Roger A, Thébaud C, Chave J. 2008. How useful is DNA barcoding for large-scale inventories of tropical trees? Presentation at a conference of the Association for Tropical Biology and Conservation; 13-19 June 2008, Paramaribo, Suriname. (10 August 2009; www.ecofog.gf/Bridge/ATBC2008/ Gonzalez.pdf)

Hardy OJ, Senterre B. 2007. Characterizing the phylogenetic structure of communities by an additive partitioning of phylogenetic diversity. Journal of Ecology 95: 493-506.

Hebert PDN, Cywinska A, Ball SL, DeWaard JR. 2003. Biological identifications through DNA barcodes. Proceedings of the Royal Society B 270: 313-321.

Hebert PDN, Penton EH, Burns JM, Janzen DH, Hallwachs W. 2004. Ten species in one: DNA barcoding reveals cryptic species in the Neotropical skipper butterfly Astraptes fulgerator. Proceedings of the National Academy of Sciences 101: 14812-14817.
Helmus MR, Bland TJ, Williams CK, Ives AR. 2007. Phylogenetic measures of biodiversity. American Naturalist 169: E68-E83.

Hickerson MJ, Meyer CP, Moritz C. 2006. DNA barcoding will often fail to discover new animal species over broad parameter space. Systematic Biology 55: 729-739.

Holmgren PK, Holmgren NH, Barnett LC. 1990. Index Herbariorum, pt. 1: The Herbaria of the World. New York Botanical Garden.

Hubbell SP. 2001. The Unified Neutral Theory of Biodiversity and Biogeography. Princeton University Press.

Hubbell SP, Foster RB. 1983. Diversity of canopy trees in a Neotropical forest and implications for conservation. Pages 25-41 in Sutton SL, Whitmore TC, Chadwick AC, eds. Tropical Rain Forest: Ecology and Management. Blackwell.

Hubbell SP, He F, Condit R, Borda-de-Água L, Kellner J, ter Steege H. 2008. How many tree species are there in the Amazon and how many of them will go extinct? Proceedings of the National Academy of Sciences 105: 11498-11504.

Jackson RB, Moore LA, Hoffmann WA, Pockman WT, Linder CR. 1999. Ecosystem rooting depth determined with caves and DNA. Proceedings of the National Academy of Sciences 96: 11387-11392.

Janzen DH. 2004a. Now is the time. Philosophical Transactions of the Royal Society B 359: 731-732.

— 2004b. Setting up tropical biodiversity for conservation through non-damaging use: Participation by parataxonomists. Journal of Applied Ecology 41: 181-187.

Jørgensen PM, León-Yánez S. 1999. Catalogue of the Vascular Plants of Ecuador. Missouri Botanical Garden.

Jurado-Rivera JA, Vogler AP, Reid CAM, Petitpierre E, Gomez-Zurita J. 2009. DNA barcoding insect-host plant associations. Proceedings of the Royal Society B 276: 639-648.

Kembel SW, Hubbell SP. 2006. The phylogenetic structure of a Neotropical forest tree community. Ecology 87: S86-S99.

Knapp S, Lamas G, Lughadha EN, Novarino G. 2004. Stability or stasis in the names of organisms: The evolving codes of nomenclature. Philosophical Transactions of the Royal Society B 359: 611-622.

Kress WJ. 2004. Paper floras: How long will they last? A review of Flowering Plants of the Neotropics. American Journal of Botany 91: 2124-2127.

Kress WJ, Erickson DL. 2007. A two-locus global DNA barcode for land plants: The coding $r b c L$ gene complements the non-coding $\operatorname{trnH}$-psbA spacer region. PLoS ONE 2: e508. doi:10.1371/journal.pone.0000508

-2008. DNA barcoding — a windfall for tropical biology? Biotropica 40: 405-408.

Kress WJ, Wurdack KJ, Zimmer EA, Weigt LA, Janzen DH. 2005. Use of DNA barcodes to identify flowering plants. Proceedings of the National Academy of Sciences 102: 8369-8374.

Kress WJ, Erickson DL, Jones FA, Swenson NG, Perez R, Sanjur O, Bermingham E. 2009. Plant DNA barcodes and a community phylogeny of a tropical forest dynamics plot in Panama. Proceedings of the National Academy of Sciences. Forthcoming.

Lahaye R, Van der Bank M, Bogarin D, Warner J, Pupulin F, Gigot G, Maurin O, Duthoit S, Barraclough TG, Savolainen V. 2008. DNA barcoding the floras of biodiversity hotspots. Proceedings of the National Academy of Sciences 105: 2923-2928. doi:10.1073/pnas.0709936105

Lavin M. 2006. Floristic and geographical stability of discontinuous seasonally dry tropical forests explains patterns of plant phylogeny and endemism. Pages 433-447 in Pennington RT, Lewis GP, Ratter JA, eds. Neotropical Savannas and Seasonally Dry Forests: Plant Diversity, Biogegoraphy and Conservation. CRC Press.

Leigh EG, Davidar P, Dick CW, Puyravaud J-P, Terborgh J, Ter Steege H, Wright SJ. 2004. Why do some tropical forests have so many kinds of trees? Biotropica 36: 447-473.

Meyer CP, Paulay G. 2005. DNA barcoding: Error rates based on comprehensive sampling. PLoS Biology 3: 1-10.

Moritz C, Cicero C. 2004. DNA barcoding: Promise and pitfalls. PLoS Biology 2: 1529-1531.

Namroud MC, Beaulieu J, Juge N, Laroche J, Bousquet J. 2008. Scanning the genome for gene single nucleotide polymorphisms involved in adaptive 
population differentiation in white spruce. Molecular Ecology 17: 3599-3613.

Newmaster SG, Fazekas AJ, Steeves RAD, Janovec J. 2008. Testing candidate plant barcode regions in the Myristicaceae. Molecular Ecology Resources 8: $480-490$

Pennington RT, Dick CW. 2004. The role of immigrants in the assembly of the South American rainforest tree flora. Philosophical Transactions of the Royal Society B 359: 1611-1622.

Phillips OL, et al. 2009. Drought sensitivity of the Amazon rainforest. Science 323: 1344-1347.

Prance GT, Beentje H, Dransfield J, Johns R. 2000. The tropical flora remains undercollected. Annals of the Missouri Botanical Garden 87: 67-71.

Pritchard JK, Stephens JC, Donnelly P. 2000. Inference of population structure using multilocus genotype data. Genetics 155: 945-959.

Ratnasingham S, Hebert PDN. 2007. BOLD: The Barcode of Life Data System (www.barcodinglife.org). Molecular Ecology Notes 7: 355-364.

Raven PH, Axelrod DI. 1974. Angiosperm biogeography and past continental movements. Annals of the Missouri Botanical Garden 61: 539-673.

Richardson JE, Pennington RT, Pennington TD, Hollingsworth PM. 2001. Rapid diversification of a species-rich genus of Neotropical rain forest trees. Science 293: 2242-2245.

Ricklefs RE. 2004. A comprehensive framework for global patterns in biodiversity. Ecology Letters 7: 1-15.

Ruokolainen K, Tuomisto H, Kalliola R. 2005. Landscape heterogeneity and species diversity in Amazonia. Pages 251-270 in Bermingham E, Dick CW, Moritz C, eds. Tropical Rainforests: Past, Present, and Future. University of Chicago Press.

Schemske DW. 2002. Ecological and evolutionary perspectives on the origins of tropical diversity. Pages 163-173 in Chazdon RL, Whitmore TC, eds. Foundations of Tropical Forest Biology. University of Chicago Press.

Scholes RJ. 2008. Ecology: Toward a global biodiversity observing system. Science 321: 1044-1045.

Silvera K, Skillman JB, Dalling JW. 2003. Seed germination, seedling growth and habitat partitioning in two morphotypes of the tropical pioneer tree Trema micrantha in a seasonal forest in Panama. Journal of Tropical Ecology 19: 27-34.

Stebbins GL. 1974. Flowering Plants: Evolution above the Species Level. Belknap.
Stevens PF. 2001 et seq. Angiosperm Phylogeny Website. (5 August 2009; www.mobot.org/MOBOT/research/APweb)

Swenson NG. 2009. Phylogenetic resolution and quantifying the phylogenetic diversity and dispersion of communities. PLoS ONE 4: e4390.

ter Steege H, et al. 2006. Continental-scale patterns of canopy tree composition and function across Amazonia. Nature 443: 444-447.

Valencia R, Foster RB, Villa G, Condit R, Svenning JC, Hernández C, Romoleroux K, Losos E, Magård E, Balslev H. 2004. Tree species distributions and local habitat variation in the Amazon: Large forest plot in eastern Ecuador. Journal of Ecology 92: 214-229.

Valentini A, et al. 2009. New perspectives in diet analysis based on DNA barcoding and parallel pyrosequencing: The trnL approach. Molecular Ecology Resources 9: 51-60.

Vamosi SM, Heard SB, Vamosi JC, Webb CO. 2009. Emerging patterns in the comparative analysis of phylogenetic community structure. Molecular Ecology 18: 572-592.

Webb CO, Donoghue MJ. 2005. Phylomatic: Tree assembly for applied phylogenetics. Molecular Ecology Notes 5: 181-183.

Wheeler QD. 2004. Taxonomic triage and the poverty of phylogeny. Philosophical Transactions of the Royal Society B 359: 571-583.

Wikstrom N, Savolainen V, Chase M. 2001. Evolution of the angiosperms: Calibrating the family tree. Proceedings of the Royal Society B 268: 2211-2220.

Wilson EO. 2000. A global biodiversity map. Science 289: 2279-2279.

Wolfe KH, Li W-H, Sharp PM. 1987. Rates of nucleotide substitution vary greatly among plant mitochondrial, chloroplast, and nuclear DNAs. Proceedings of the National Academy of Sciences 84: 9054-9058.

Yesson C, Russell SJ, Parrish T, Dalling JW, Garwood NC. 2004. Phylogenetic framework for Trema (Celtidaceae). Plant Systematics and Evolution 248: 85-109.

ChristopherW.Dick (cwdick@umich.edu) is with the University of Michigan Herbarium and the Department of Ecology and Evolutionary Biology at the University of Michigan in Ann Arbor; he is also associated with the Smithsonian Tropical Research Institute in Balboa Ancón, Panama. W. John Kress (kressj@si.edu) is with the Department of Botany at the National Museum of Natural History, Smithsonian Institution, in Washington, DC, and an adjunct professor at the Xishuangbanna Tropical Botanical Garden, Chinese Academy of Sciences, in Yunnan, China. 

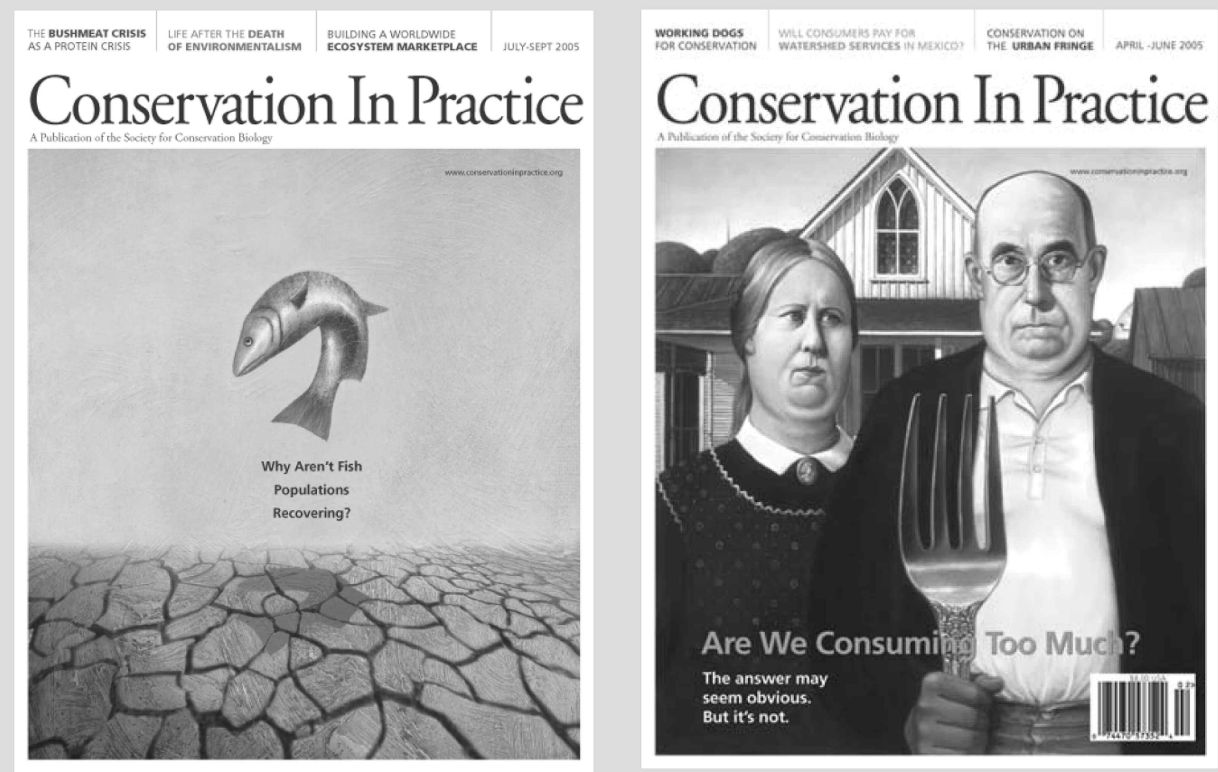

\section{Seven Conservation Partners. One Extraordinary Magazine.}

Conservation In Practice is a single magazine supported by an extraordinary partnership of some of the most influential organizations in the field. These partners have invested in this unique magazine to create a forum for frank conversations and bold ideas - beyond the boundaries of any one organization.

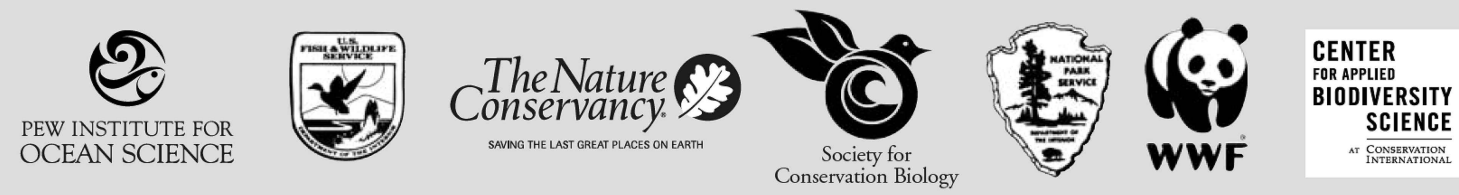

\section{See For Yourself}

Take a Virtual Tour of the Magazine www.conservationinpractice.org 